\title{
EDITORIAL
}

\section{CAEP standards: Ivory tower emergency medicine?}

\author{
Sam G. Campbell, MB, BCh
}

See related article on page 443

Version française à la PAge 464

$\mathrm{T}$ he Canadian Association of Emergency Physicians (CAEP) sepsis guidelines by Green and colleagues ${ }^{1}$ presents an excellent, user-friendly and evidence-based guideline for the management of sepsis in a tertiary care emergency environment. Potentially avoidable deaths due to sepsis have long been recognized, as has the potential to improve the situation with appropriate emergency department (ED) therapy. ${ }^{2-6}$ In 2004, a document was produced jointly by 11 international organizations, including the American College of Emergency Physicians, ${ }^{7}$ to guide sepsis treatment throughout the continuum of hospital care, including the ED.

The initial recognition and treatment of sepsis is in most cases conducted not by intensivists in the intensive care unit, but by front-line physicians in EDs or urgent care centres. In emergency medicine, the option of referring septic patients to other disciplines in the time demanded by the situation is often not feasible. It is appropriate, therefore, that guidelines aimed specifically at emergency physicians (EPs) are produced. Canadian EPs should be proud that their organization is the first emergency medicine association to independently develop and advocate such guidelines specifically for the use of its members.

The mission statement of the CAEP Standards Committee includes the recognition of "a shared responsibility in ensuring that the standard of care provided in every emergency setting is of the highest quality and is based on the best possible scientific information." In 2007, the Standards Committee adopted the Appraisal of Guidelines Research and Evaluation (AGREE) guideline appraisal instrument $^{9}$ for the evaluation of guidelines submitted to CAEP. The sepsis guidelines submitted by Green and colleagues were found to meet the prescribed standard and the adoption thereof was recommended to the CAEP board.

In the spirit of the above mission statement, it is appropriate that CAEP encourages its members to both produce documents like this and to adhere to the guidelines where possible. The "where possible" clarification raises many questions:

- Who should be expected to follow them, and how completely?

- Could physicians be "judged" (to their detriment) for not doing so?

- Should hospital administrators ensure that we have the equipment and training to adhere to these standards?

- If I am a family physician (FP) providing emergency care and am unfamiliar with a large number of the recommendations, where do these guidelines put me?

Indeed, the Standards Committee mission statement includes the following proviso: "To ensure that the proposed practice standards are flexible enough to allow them to be applied in various emergency settings that consider geographical, political, and cultural differences across the country.",

Although the Standards Committee found the guidelines in question to be simple and clear, some of the recommendations by Green and coauthors (such as central venous or arterial lines) are not routinely practised in many rural Canadian EDs, nor are medications such as activated protein $\mathrm{C}$ likely to be on the formulary in those same hospitals. Many non-emergency specialist health care providers in such environments might feel uncomfortable performing some of the recommendations regarding, for example, the use of inotropes and mechanical ventilation. Rural physicians provide care to $31.4 \%$ of the population. ${ }^{10}$ Should CAEP be promoting guidelines that might not fit their environment?

Chair, CAEP Standards Committee; from the Departments of Emergency Medicine, Dalhousie University and Queen Elizabeth II Health Science Centre, Halifax, NS

All editorial matter represents the views of the authors and not necessarily those of CJEM or the Canadian Association of Emergency Physicians.

CJEM 2008;10(5):461-3 
The CAEP Standards Committee feels strongly that guidelines endorsed by our national organization should unapologetically represent "state of the art" care. In no way should guidelines be designed to guide the minimum level of care that could realistically be provided in every single Canadian ED. They should represent the "gold standard" of care to which we should all strive (within our idiosyncratic capabilities), as opposed to a standard against which we should all be judged. Having said that, this expectation of doing our best under the circumstances should not allow us to tolerate a substandard level of expertise. Although it is unrealistic to expect us to all be experts, a certain level of expertise should be a nonnegotiable attribute of any Canadian EP. By accepting employment as an EP, you are telling the public that you are prepared to properly manage anything that they might reasonably be expected to throw at you (John M. Tallon, AIME Roadshow: unpublished communication), with the full spectrum of sepsis being a good example.

Non-emergency specialists (usually FPs) do and will continue to treat patients who present to Canadian hospitals for urgent or emergency care, just as they will also continue to provide obstetric, medical and surgical care in addition to primary care. Although in the majority of cases they will provide excellent care, it is as unreasonable to expect them to carry the range of skills of an emergency specialist as it would be to expect them to have those of an obstetrician, internist or surgeon. They should not be judged according to standards prescribed for EPs. The public, however, should be aware that this is the case (the woman giving birth knows that the FP delivering her child is not an obstetrician). The standards to which FPs are held are the issue of the College of Family Physicians of Canada, not of CAEP. Anyone who calls him- or herself an emergency specialist, or who works in an ED, should meet the standards prescribed for the role.

The issue of EDs that are staffed by non-EPs is beyond the scope of this discussion, but could be managed by the honest policy of not calling them EDs! The public would be comfortable going to the more honestly called urgent care centres (or another name, given that this name already has widespread usage) and would know what they should reasonably expect. This issue has been discussed previously in CJEM. ${ }^{11-13}$ The distinction is not intended to imply that FPs are not competent to manage much of the acute care required by Canadians (as they are to produce much of the obstetric or medical care). Nor should it be interpreted to suggest that these FPs are not an important part of CAEP. If anything, this protects the FP who chooses to provide emergency care from being held to the unreason- able standard of a full-time EP, while also having to maintain the skills and knowledge required for the rest of his or her job.

It is important to note that this is not a "turf" argument, in the fashion of the recent objections of anesthesiologists to the ED use of propofol, or of radiologists to focused abdominal sonogram for trauma (FAST). CAEP standards are ultimately for the benefit of patients, not physicians. Hopefully they will improve emergency care, regardless of who is carrying them out. They serve as a standard toward which any practitioner should strive. If the recommendations are out of any one physician's scope or capability, it will help guide the direction in which the patient could be steered. Similarly, these guidelines may assist the consultant internist or intensivist in his or her endeavours.

Guideline and standard development is, and will continue to be, a work in progress. Like any specialty society, CAEP should continue to strive for excellent care for patients needing the services of its discipline. This includes supporting all physicians who are providing these services, even those practising where state-of-the-art care is not a realistic option, by assisting them to adapt CAEP standards to their areas of practice through continuing medical education endeavours and by collaborating with other professional groups, such as the Society of Rural Physicians of Canada.

If at first perusal physicians do not think that these guidelines will help them in their rural ED, I would suggest that they read them again, asking not "Is this for me?" but "What is there in here that I can use?" They should adapt and adopt as many of the suggestions as they can, and understand the purpose of the others, so that they can identify cases that would be well served by emergent transfer for the intervention in question. One should not be unreasonably judged against these guidelines, but as committed health care providers, we should all continue to move as close to the gold standard as we can.

Competing interests: None declared.

\section{References}

1. Green RS, Djogovic D, Gray S, et al. Canadian Association of Emergency Physicians sepsis guidelines: the optimal management of severe sepsis in Canadian emergency departments. CJEM 2008;10:443-59.

2. Rivers E, Nguyen B, Havstad S, et al. Early goal-directed therapy in the treatment of severe sepsis and septic shock. N Engl J Med 2001;345:1368-77.

3. Nguyen HB, Rivers EP, Abrahamian FM, et al. Severe sepsis and septic shock: review of the literature and emergency department management guidelines. Ann Emerg Med 2006;48:28-54. 
4. Raghavan M, Marik PE. Management of sepsis during the early "golden hours". J Emerg Med 2006;31:185-99.

5. De Miguel-Yanes JM, Andueza-Lillo JA, González-Ramallo $\mathrm{VJ}$, et al. Failure to implement evidence-based clinical guidelines for sepsis at the ED. Am J Emerg Med 2006;24:553-9.

6. Rivers EP, McIntyre L, Morro DC, et al. Early and innovative interventions for severe sepsis and septic shock: taking advantage of a window of opportunity. CMAJ 2005;173:1054-65.

7. Surviving Sepsis Campaign. International guidelines for management of severe sepsis and septic shock 2008. Crit Care Med 2008;36:296-327.

8. CAEP Standards Committee. Terms of reference. Available: www.caep.ca/page. asp?id=6C8BB1063C594F598FABF3BFE5 DD0C1C (accessed 2008 July 21).
9. The AGREE Collaboration. Appraisal of Guidelines for Research \& Evaluation (AGREE) Instrument. Available: www.agreecolla boration.org (accessed 2008 July 20).

10. Society of Rural Physicians of Canada. Available: www.srpc.ca/ (accessed 2008 July 21).

11. Innes G. Thinking outside the box [editorial]. CJEM 2002;4:316.

12. Brothers A. Thinking outside the box [letter]. CJEM 2002;4:387.

13. Laroque D. Thinking outside the box [letter]. CJEM 2002;4:387.

Correspondence to: Dr. Sam G. Campbell, Department of Emergency Medicine, QE II HSC, Dalhousie University, 3021-1796 Summer St., Halifax NS B3H 3A7; EMSGC@cdha.nshealth.ca 